\title{
Surfactant Content and Type II Cell Development in Fetal Guinea Pig Lungs during Prenatal Starvation
}

\author{
YUE LIN AND ANDREW J. LECHNER \\ Department of Physiology, St. Louis University School of Medicine, St. Louis, Missouri 63104
}

\begin{abstract}
Prenatal caloric restriction in guinea pigs causes intrauterine growth retardation and reduced neonatal viability and surfactant phosopholipid (PL). We report here fetal surfactant levels in this model, and correlate total lung PL with ultrastructural maturation of surfactant type II cells and lamellar bodies (LB). Pregnant guinea pigs were fed ad libitum throughout their 68-d gestation (control), or fed $50 \%$ rations from d 45 until term (starved). Fetal lungs were examined at d 55, 60, and 65 for PL content and composition, including disaturated phosphatidylcholine (DPC), and compared with neonates for both groups. Lung lobes were analyzed ultrastructurally in d $\mathbf{6 5}$ fetuses for the numerical, volume, and surface densities of type II cells and the volume densities of LB. Prenatal starvation caused significant intrauterine growth retardation at all ages; body and dry lung weights were reduced on $d 65$ by 26 and $23 \%$, respectively. By d 55 and thereafter, starvation decreased total lung PL by $43-45 \%$ but did not alter PL composition. On $d 65$, the total lung volumes and relative numbers, surface densities, and volumes of type II cells in tissue and the relative volumes of $\mathrm{LB}$ within type II cells did not differ by caloric regimen. Thus, starved and control fetuses had similar total volumes of LB per lung (13-15 $\mu \mathrm{L}$ ), although starved animals had significantly less lung DPC. Although the total volume of $L B$ per lung correlated well with total lung DPC from d 55 through birth in controls, starvation led to a significant departure from this relationship. These results suggest that the concentration of DPC within LB can vary markedly without changing the size and appearance of the $\mathrm{LB}$, or that the reduced amounts of DPC in starved fetuses represent deficiencies of surfactant from non-LB compartments. (Pediatr Res 29: 288-291, 1991)
\end{abstract}

\section{Abbreviations}

LB, lamellar bodies

PL, phospholipid

DPC, disaturated phosphatidylcholine

IUGR, intrauterine growth retardation

Maternal malnutrition during gestation decreases fetal growth and development and causes IUGR. Starvation of pregnant animals yields smaller fetuses that do not survive parturition or newborns that fail to thrive postnatally $(1-4)$. Compared with

Received August 1, 1990; accepted October 31, 1990.

Correspondence and reprints: Dr. Andrew J. Lechner, Department of Physiology, St. Louis University School of Medicine, 1402 South Grand Blvd., St. Louis, MO 63104 .

Supported by Grant HL-37386 from the National Heart, Lung, and Blood Institute controls, the lungs of starved rat fetuses appear to have reduced septation and delayed surfactant type II cell maturation, including the subjective impression of fewer LB in those cells (5). In newborn guinea pigs, the total lung weight, DNA content, alveolar surface area, compliance, and surfactant content are reduced significantly when pregnant animals receive $50 \%$ rations of their normal food during the last 3 wk of their 68 -d gestation $(4,6)$. However, the fetal maturation of alveolar type II cells after such malnutrition-induced IUGR has never been accurately quantitated in any of these animal models.

There are few data on the cellularity of normal human fetal lungs, and none for human hypoplastic lungs caused by or associated with any form of IUGR or prematurity (7). This is despite a mortality rate in neonates weighing $<2500 \mathrm{~g}$ that is 40 times that of larger neonates during the 1st postnatal month, and that smaller neonates show a higher incidence of neonatal respiratory distress $(8,9)$. Thus, animal models of IUGR may improve current understanding of the pulmonary consequences of similar human intrauterine stress. We have asked two fundamental questions using such a model in guinea pigs. First, how does maternal starvation affect the maturation of fetal type II cells, including their total numbers, average dimensions, and contents of LB? Second, do changes in type II cell structural development during this stress correlate with the content and composition of surfactant PL found in such growth-retarded lungs? We have used ultrastructural morphometry and PL analyses in time-dated fetuses in our attempt to answer these questions.

\section{MATERIALS AND METHODS}

Pregnant Hartley-strain guinea pigs with verified insemination dates were obtained from Camm Research (Wayne, NJ) and individually caged at $22^{\circ} \mathrm{C}(2)$. Controls received food ad libitum throughout their pregnancies (Guinea Pig Chow no. 5025, Ralston Purina Co., St. Louis, MO, containing $4.0 \%$ fat, $18.5 \%$ protein, $11.5 \%$ fiber, and $175 \%$ of known vitamin and mineral requirements). Experimentals were fed ad libitum until d 45 of gestation, and then were fed $50 \%$ rations of the average amount consumed by controls at the same day of gestation (starvation). In practice, this $50 \%$ ration was equal to $20 \mathrm{~g}$ of Chow/d until parturition at 67-69 d of gestation. No evidence of coprophagia was noted in any animals, and fecal pellets were similar in size and apparent degree of hydration between treatment groups. Vitamin $C$ was added to the water supply of starved animals, as previously described $(2,4)$. All aspects of the experimental protocol were reviewed and approved by the Animal Care Committee of St. Louis University Medical Center, and all experiments were conducted in accordance with the highest standards of humane care.

For PL analyses, the lungs of viable control and starved fetuses were studied at 55,60 , and $65 \mathrm{~d}$ of gestation. Fetuses were obtained by cesarean section under maternal anesthesia (Na- 
pentobarbital, $35 \mathrm{mg} / \mathrm{kg}$, intraperitoneally), and their sex and body weight were determined. Preliminary attempts to lavage fetal lungs as done for newborn guinea pigs (6) were not successful, due to airway fluid content and tissue fragility, particularly in the starved groups. Therefore, unlavaged lungs were excised intact and homogenized in 20 times their fresh weight of chloroform:methanol $(2: 1)$, extracted, and filtered $(6,10)$. Filtrates were dried under $\mathrm{N}_{2}$, resolubilized in chloroform, and assayed for total phosphorus (11) and constituent PL using two-dimensional thinlayer chromatography $(6,12)$. PL were visualized with iodine vapors on the plates (silica gel $60,0.25 \mathrm{~mm}$ layer, Soft-Plus EM5782, E. Merck, Darmstadt, Germany) and were run against highly purified standards (Supelco, Bellefonte, PA), with spots scraped and then also analyzed for phosphorus content $(6,11)$.

Ultrastructural features of lungs from control and starved fetuses were compared at $d 65$ of gestation because by this age the alveoli are normally fully matured, including the LB within type II cells (13-15). After lung collapse and tracheal intubation in situ, lungs were fixed by intratracheal instillation of $2 \%$ glutaraldehyde in cacodylate buffer at $20 \mathrm{~cm} \mathrm{H}_{2} \mathrm{O}$ transpulmonary pressure for $60 \mathrm{~min}(4,15)$. Fixed lungs were excised, the large airways were removed to the level of the primary bronchi, and total fixed lung volume was measured by fluid displacement in saline. Lungs were stored in fresh buffered glutaraldehyde overnight at $5^{\circ} \mathrm{C}$ before dicing $(4,15)$.

Five blocks 1-2 mm on a side were cut from midplanar sections of each left cranial and caudal lobe (10 blocks per animal), postfixed in $\mathrm{OsO}_{4}$, and processed for embedding in Spurr's medium (15). Extensive regional sampling within these lobes has demonstrated both interlobar and intralobar homogeneity of lung development in control fetal guinea pigs $(13,14)$, and preliminary analyses indicated similar findings for the starved fetuses at d 65 . Semithin $(0.5-\mu \mathrm{m})$ sections were stained with toluidine blue and examined with light microscopy to determine the fraction of total lung volume composed of respiratory parenchyma (i.e. the fraction of total lung volume exclusive of conducting zone volume) using a point-counting eyepiece reticule $(13-15)$.

Thin $(50-\mathrm{nm})$ sections were stained for electron microscopy with lead citrate and uranyl acetate, mounted on coated 200 mesh copper grids, and examined on a JEOL $100 \mathrm{~S}$ electron microscope (JEOL Inc., Tokyo, Japan). Ten negatives were taken from each grid using a stratified sampling strategy at $2000 \times$ and 10 negatives at $4000 \times$ magnification (13). The 100 prints per animal ( $3 \times$ enlargements) made from the $2000 \times$ negatives were used to measure type II cell volume density (the percent of respiratory parenchymal tissue composed of type II cells) and type II cell surface density (the aggregate surface area in $\mathrm{cm}^{2}$ of type II cells per $\mathrm{cm}^{3}$ of respiratory parenchymal tissue) in each fetus using an overlay grid of 84 test lines and 168 endpoints (4, 13-15). The numerical density of type II cells (the number of type II cells per $\mathrm{cm}^{3}$ of respiratory parenchymal tissue) for each grid was determined by directly counting nuclear profiles within 10 sequential grid squares on the electron microscope screen at $4000 \times$. These counts included all type II cells whose nuclei overlapped the upper and left grid borders but not the lower or right borders; nuclear diameters were measured as reported elswhere $(13,14)$. Photographic enlargements made from the $4000 \times$ negatives (100 per animal) were used to measure the volume densities of LB in type II cells (the percent of type II cell volume composed of LB) for each fetus using a dense-array photographic overlay grid (13). The total volume of LB per lung was then calculated for each animal from that animal's volume density of LB in type II cells, total fixed lung volume, and the fraction of total lung volume composed of respiratory parenchyma (13-15).

Data have been presented as means \pm SEM, with groups compared for phospholipid data at all ages by analysis of variance and Dunnett's post hoc $t$ test $(14,16)$. The $t$ test was used to compare ultrastructural data between control and starved fetuses at $\mathrm{d} 65$ (16). An outcome of $p<0.05$ was considered statistically significant.

\section{RESULTS}

Age-matched fetuses were studied from four to five litters per treatment to control for any maturational differences among litters; there were no significant differences in mean total litter size or number of viable fetuses by treatment (total fetuses/litter $=4.1 \pm 0.3, n=27$ litters) $(2,4)$. No significant differences were found due to sex, and data were pooled by age for comparisons between control and starved treatments. Starvation caused significant IUGR throughout gestation such that by $\mathrm{d} 65$, body

Table 1. Body and lung wt and total lung inorganic phosphorus (means $\pm S E M$ ) in control and starved guinea pigs

\begin{tabular}{rrrrrr}
\hline Age & Group & $n$ & Body wt $(\mathrm{g})$ & $\begin{array}{c}\text { Dry lung wt } \\
(\mathrm{mg})\end{array}$ & $\begin{array}{c}\text { Total lung } \\
\text { inorganic } \\
\text { phosphorus }(\mu \mathrm{g})\end{array}$ \\
\hline Day 55 & Control & 21 & $57.2 \pm 1.7$ & $157.1 \pm 5.0$ & $370.4 \pm 54.8$ \\
& Starved & 9 & $48.5 \pm 2.1^{*}$ & $150.8 \pm 9.6$ & $200.6 \pm 31.3^{*}$ \\
Day 60 & Control & 17 & $71.1 \pm 2.4$ & $204.2 \pm 11.2$ & $600.2 \pm 142.8$ \\
& Starved & 8 & $59.5 \pm 1.7^{*}$ & $165.9 \pm 6.0^{*}$ & $328.6 \pm 101.4^{*}$ \\
Day 65 & Control & 20 & $99.9 \pm 3.7$ & $248.0 \pm 12.1$ & $976.6 \pm 99.1$ \\
& Starved & 13 & $74.4 \pm 3.2^{*}$ & $192.1 \pm 8.0^{*}$ & $560.9 \pm 79.3^{*}$ \\
Newborn† $\dagger$ Control & 13 & $117.2 \pm 5.5$ & $254.0 \pm 13.0$ & $1752.8 \pm 119.6$ \\
& Starved & 21 & $69.4 \pm 2.3^{*}$ & $193.0 \pm 7.0^{*}$ & $1136.4 \pm 61.3^{*}$ \\
\hline
\end{tabular}

$* p<0.05$ vs controls of same age.

$\dagger$ Newborn data from ref. 6 .

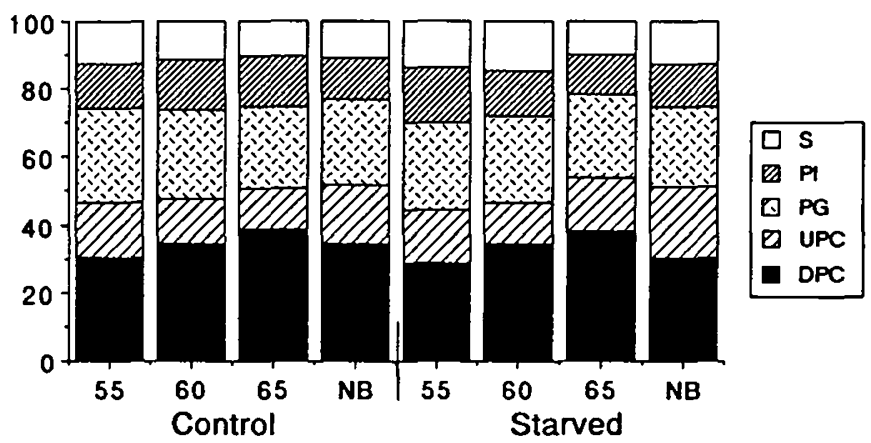

Gestational Age (days)

Fig. 1. Lung PL composition (\%) in fetal guinea pigs at 55,60, and $65 \mathrm{~d}$ of gestation. For clarity, group means are shown without error bars ( $n$ values in Table 1); by analysis of variance, there were no significant differences between age-matched treatments or within groups at different ages. Abbreviations are: $S$, sphingomyelin; $P I$, phosphatidylinositol; $P G$, phosphatidylglycerol; $U P C$, unsaturated phosphatidylcholine. Data for newborn guinea pigs $(N B)$ are from ref. 6 .

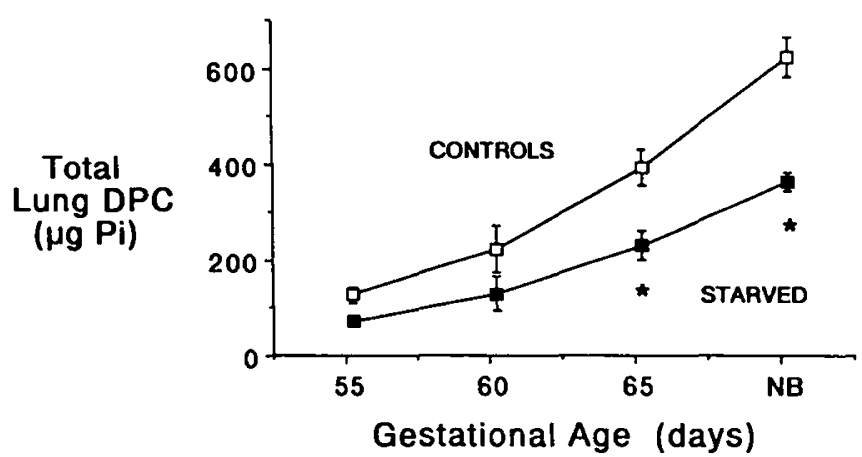

Fig. 2. Total lung DPC in control and starved fetal guinea pigs. Values are means $\pm \operatorname{SEM}(n$ values in Table 1$) .{ }^{*} p<0.01$ between treatments at the same age. Data for newborn guinea pigs $(N B)$ are from ref. 6 . 
Table 2. Body, lung, and type II cell data (means \pm SEM) in fetal guinea pigs at 65 d of gestation ( $n=6$ in each group)

\begin{tabular}{lcc}
\hline \multicolumn{1}{c}{ Parameter } & Control & Starved \\
\hline Fetal body weight $(\mathrm{g})$ & $95.8 \pm 7.9$ & $75.8 \pm 6.2^{*}$ \\
Total fixed lung volume $(\mathrm{mL})$ & $5.0 \pm 0.18$ & $4.8 \pm 0.4$ \\
Respiratory parenchymal fraction of lung volume & $0.95 \pm 0.01$ & $0.94 \pm 0.02$ \\
Type II cell volume density $(\%)$ & $11.2 \pm 0.8$ & $14.4 \pm 2.0$ \\
Type II cell numerical density $\left(\times 10^{7} / \mathrm{mL}\right)$ & $54.4 \pm 4.3$ & $46.0 \pm 4.9$ \\
Type II cell surface density $\left(\mathrm{cm}^{-1}\right)$ & $959.2 \pm 154.9$ & $799.7 \pm 65.5$ \\
Volume density of LB in type II cells $(\%)$ & $16.0 \pm 1.5$ & $17.7 \pm 0.6$ \\
\hline
\end{tabular}

${ }^{*} p<0.05$ vs controls. See the text for details of the volume, numerical, and surface density terms for type II cells and LB.

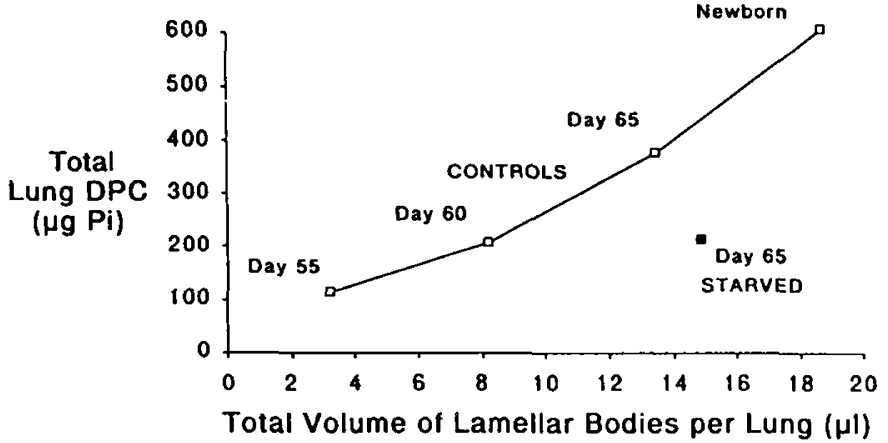

Fig. 3. Group means by gestational age and treatment of total lung DPC and total lung volume of LB within recognizable type II cells. Mean lung LB volumes for d 55, 60, and newborn controls are from ref. 13 .

weight was reduced $26 \%$ and dry lung weight $23 \%$ compared with controls (Table 1). Starvation also reduced the total lung PL by $43-45 \%$ at all ages (Table 1), similar to data in newborn guinea pigs from starved litters (6). Lung PL compositions were similar between treatments, and the percent DPC increased with age in all fetal animals (Fig. 1). Although the percent DPC decreased slightly from $\mathrm{d} 65$ to birth in both groups, total lung DPC increased through parturition (Fig. 2). The percentages of other surfactant PL were similar in control and starved groups (Fig. 1).

Unlike body weight and dry lung weight, total fixed lung volumes and their fractions of respiratory parenchyma were not significantly different between control and starved fetuses at $d$ 65 (Table 2). Ultrastructural analyses of type II cells indicated no significant interlobar differences for any animal, and data were then pooled by animal for intergroup comparisons. The distribution of type II cells in the respiratory parenchyma was not affected by prenatal starvation, with similar values to controls for the numerical, volume, and surface densities of type II cells (Table 2). The volume densities of LB within type II cells were also comparable in control and starved fetuses at $\mathrm{d} 65$, averaging $17 \%$ of type II cell volume (Table 2 ). Thus, the total volumes of LB per lung were similar between groups at $d 65$, although the starved animals departed from the linear relationship between total lung DPC and total lung LB volume noted for controls (Fig. 3) (13).

\section{DISCUSSION}

Prenatal starvation reduces fetal and newborn lung surfactant to similar degrees in both rats and guinea pigs, and lung DPC is usually reduced to a greater extent than lung dry weight or cellularity in the same animals $(3,6,17)$. Altered type II cell maturation would thus seem to be a likely determinant of the morbidity and respiratory distress noted in neonates from starved litters or other forms of IUGR (7), despite a lack of direct information. In starved fetal rats, Curle and Adamson (5) found qualitatively reduced saccular differentiation, diminished epithelial attenuation, and reduced amounts of histochemically identifiable surfactant within presumptive type II cells. In previous studies of newborn guinea pigs from starved litters, we examined only the volume density of type II cells, which was not significantly changed by starvation $(4,18)$. However, both the volume density of LB within type II cells and the total lung LB volume increase linearly with gestational age in normal guinea pig fetuses (13), and these parameters correlate with linear increases in total PL from normal fetal lungs (Figs. 2 and 3 ).

Considering this histologic and biochemical background, it was surprising that the number of type II cells and their content of LB were not affected by prenatal starvation. Having performed the same assays on control and starved groups and eliminated regional heterogeneity and sexual differences as confounding variables, these results are not likely artifactual. Thus, although LB volume density in type II cells and total lung LB volume are excellent predictors of surfactant content in normal perinatal guinea pigs, that relationship is altered by prenatal starvation. Because type II cells from both control and starved animals contained about $16 \%$ LB by volume, these LB may have contained different densities or concentrations of DPC in the two treatment groups. However, no evidence exists to support such a conclusion. Gail et al. (19) reported no decreases in the volume density of LB within type II cells of fasted adult rats compared with controls, despite reductions in tissue of DPC of $27 \%$ and lavage DPC of $40 \%$ (19). A subsequent analysis of type II cells in lungs of 1 - to 2 -d-old rat pups from prenatally starved litters suggested that LB volume density in type II cells decreased only slightly compared with controls (20).

A more plausible explanation of the starvation-altered relationship between total lung DPC and total lung LB volume (Fig. 3 ) derives from the relatively small percentage (10-21\%) of total lung DPC that can actually be isolated from purified LB fractions of the same lungs (21-23). The large amount of non-LB lung DPC is distributed elsewhere in type II cells (including endoplasmic reticulum, Golgi apparatus, and transport vesicles) and in extracellular pools of secreted or recycled surfactant (21). Because only the LB pool of DPC was estimated morphometrically in the starved fetuses, DPC may have been depleted primarily from these other non-LB pools as a result of prenatal starvation. In newborn guinea pigs from starved litters, lavage DPC was decreased by $61 \%$, compared with only a $35 \%$ reduction in the lavaged lung tissue compartment (6). In newborn rats, the total LB content of DPC decreased slightly even as total lung DPC increased by $35 \%$ during $24 \mathrm{~h}$ of air breathing (23). Thus, the linearity between lung DPC and lung LB volume for control fetuses (Fig. 3) may mean only that the relative amount of total lung DPC that is within LB is constant over this developmental period, even though all lung DPC pools are expanding dramatically. Stresses such as parturition or prenatal starvation might then both be viewed as having perturbed primarily the non-LB pools of surfactant DPC.

To summarize, large deficiencies in pulmonary surfactant among starved guinea pig fetuses were not accompanied either by changes in PL composition or by retarded maturation of the secretory type II cells that produce this material, as assessed ultrastructurally. Decreased total lung PL also were not associated with significant changes in air-filled compliance among neonates from starved litters when adjusted for differences in lung volume and body weight (6). Nevertheless, prenatal starvation clearly has deleterious consequences on neonatal survivor- 
ship in all species examined $(1,2,4,17)$. Interestingly, concurrent administration of transplacental glucocorticoids to prenatally starved guinea pigs (dexamethasone given from d 55 until term to litters that were on $50 \%$ rations from d 45 until term) significantly alleviated the morbidity and mortality caused by malnutrition (18). The enhanced survivorship with glucocorticoids was correlated with increased total endothelial surface area and membrane diffusing capacity in treated animals, and not with increased total lung PL or other measured type II cell effects (18) Preliminary morphometry on other lung cells in the starved d 65 fetuses has indicated a significant reduction in total endothelial tissue volume (unpublished data). Thus, although type II cell maturation and surfactant production may be altered by IUGR, the retarded development of other lung cellular elements by such stress may be of equal or greater importance in determining extrauterine survival.

\section{REFERENCES}

1. Naeye RL, Freeman RK, Blanc WA 1974 Nutrition, sex, and fetal lung maturation. Pediatr Res 8:200-204

2. Lechner AJ 1984 Growth retardation and mortality in guinea pigs following perinatal starvation. Nutr Rep Int 30:1435-1447

3. Rhoades RA, Ryder DA 1981 Fetal lung metabolism: response to maternal fasting. Biochim Biophys Acta 663:621-629

4. Lechner AJ 1985 Perinatal age determines the severity of retarded lung development induced by starvation. Am Rev Respir Dis 131:638-643

5. Curle DC, Adamson LYR 1978 Retarded development of neonatal rat lung by maternal malnutrition. J Histochem Cytochem 26:401-408

6. Lechner AJ, Winston DC, Bauman JE 1986 Lung mechanics, cellularity, and surfactant after prenatal starvation in guinea pigs. J Appl Physiol 60:1610 1614
7. Langston C, Kida K, Reed M, Thurlbeck WM 1984 Human lung growth in late gestation and in the neonate. Am Rev Respir Dis 129:607-613

8. Shapiro S, McCormick MC, Starfield BH, Krisher JP, Bross D 1980 Relevance of correlates of infant deaths for significant morbidity at 1 year of age. Am J Obstet Gynecol 136:363-373

9. Hack M, Merkatz IR, Jones PK, Fanaroff AA 1980 Changing trends of neonatal and postneonatal deaths in very-low-birth-weight infants. Am J Obste Gynecol 137:797-800

10. Folch J, Lees M, Sloane Stanley GH 1957 A simple method for the isolation and purification of total lipids from animal tissues. J Biol Chem 226:497509

11. Bartlett GR 1959 Phosphorus assay in column chromatotography. J Biol Chem 234:466-468

12. Gilfillan AM Chu AJ, Smart DA, Rooney SA 1983 Single plate separation of lung phospholipids including disaturated phosphatidylcholine. J Lipid Res 24:1651-1656

13. Lin Y, Lechner AJ 1990 Ultrastructural analysis of regional type II cel development within fetal and neonatal lungs. Am J Physiol 259:L359-L364

14. Lin Y, Lechner AJ 1991 Development of alveolar septa and cellular maturation within the perinatal lung. Am J Respir Cell Mol Biol 4:59-64

15. Lechner AJ, Banchero N 1982 Advanced pulmonary development in newborm guinea pigs (Cavia porcellus). Am J Anat 163:235-246

16. Sokal RR, Rohlf FJ 1981 Biometry. WH Freeman CO, San Francisco

17. Faridy EE 1975 Effect of maternal malnutrition on surface activity of fetal lungs in rats. J Appl Physiol 39:535-540

18. Lechner AJ 1987 Interaction of prenatal starvation and dexamethasone treatment on lung development in newborn guinea pigs. Am Rev Respir Dis 135:991-996

19. Gail DB, Massaro GD, Massaro D 1977 Influence of fasting on the lung. J Appl Physiol 42:88-92

20. Massaro GD, Clerch L, Massaro D 1986 Perinatal anatomic development of alveolar type II cells in rats. Am J Physiol 251:R470-R475

21. Wright JR, Clements JA 1987 Metabolism and turnover of lung surfactant. Am Rev Respir Dis 136:426-444

22. Young SL, Kremers SA, Apple JS, Crapo JD, Brumley GW 1981 Rat lung surfactant kinetics: biochemical and morphometric correlations. J Appl Physiol 51:248-253

23. Spain CL, Silbajoris R, Young SL 1987 Alterations of surfactant pools in feta and newborn rat lungs. Pediatr Res 21:5-9 